\title{
Stimulatory Action of Prolactin on Gonadotropin Secretion in Vitro
}

\author{
Koji KUGU, Yuji TAKeTANi and Masahiko MIZUNO \\ Department of Obstetrics and Gynecology, Faculty of Medicine, \\ University of Tokyo \\ 7-3-1, Hongo, Bunkyo-ku, Tokyo, 113, Japan
}

\begin{abstract}
The action of prolactin (PRL) on the secretion of gonadotropin was investigated by means of a cell culture system of rat anterior pituitary gland. Anterior pituitary glands were removed from Wistar male rats, enzymatically digested and cultured. Luteinizing hormone $(\mathrm{LH})$ release into medium was increased by adding PRL dose-dependently in the range between $10 \mathrm{ng} / \mathrm{ml}$ and $1 \mu \mathrm{g} / \mathrm{ml}$. This effect of PRL was further augmented by the presence of either gonadotropin-releasing hormone or estradiol. The intracellular LH concentration was also increased by PRL. PRL also caused an increase in folliclestimulating hormone release into medium dose-dependently.

In conclusion, PRL was shown to stimulate the secretion of gonadotropin at the pituitary level, thus suggesting a paracrine mode of PRL action in the anterior pituitary gland.
\end{abstract}

Hyperprolactinemia is often associated with various types of menstrual disorders. However, the mechanism by which prolactin (PRL) affects the gonadal function is very controversial. To date, several data suggest an action of PRL in decreasing the release of gonadotropin-releasing hormone ( $\mathrm{GnRH})$ which consequently influences the anterior pituitary gland to reduce the secretion of gonadotropin (Bohnet et al., 1976; Aono et al., 1976; Taketani et al., 1988). On the other hand, the capacity of the anterior pituitary gland to secrete gonadotropin in response to GnRH is intact or often rather enhanced in hyperprolactinemic women (Archer et al., 1976; Chang et al., 1977; Monroe et al., 1981). Therefore, the action of PRL solely on the hypothalamus cannot

Received February 7, 1989 explain the observed clinical findings especially related to the secretion of gonadotropin.

To gain a deeper insight into the mechanism by which PRL suppresses gonadal function, the direct action of PRL at the pituitary gland was examined by means of an anterior pituitary cell culture system.

\section{Materials and Methods}

\section{(1) Materials}

The following materials were purchased: collagenase, insulin and estradiol from Sigma, and GnRH from Tanabe. Ovine PRL was kindly provided from NIADDK, NIH.

\section{(2) Cell culture}

Adult male Wistar rats kept in an environment at an adequate temperature, humidity and 
day-night cycle were used throughout these studies. Rats were anesthetized by ether and decapitated. Anterior pituitary glands were removed, chopped with a razor and enzymatically digested in the Medium 199 supplemented with $0.1 \%$ of collagenase and $1 \%$ of bovine serum albumin (BSA) for 30 minutes. Digested pieces were washed twice with Medium 199 containing $1 \%$ BSA and then suspended in Medium 199 containing $10 \%$ of fetal bovine serum and 5 $\mu \mathrm{g} / \mathrm{ml}$ of insulin, yielding a cell density of about $15 \times 10^{4} / \mathrm{ml}$. Each of 24 flat bottom cell wells was filled with $0.5 \mathrm{ml}$ of the above medium containing dispersed cells. After 24 hours of culture, the medium was changed and various agents as indicated were added to the culture medium. The culture was continued for another 48 hours and the culture medium was aspirated and kept frozen until it was assayed. The cultured cells were immersed in $0.5 \mathrm{ml}$ of phosphate buffered saline and lysed by thawing and freezing three times. After centrifugation at $3,000 \mathrm{rpm}$ for 10 minutes, the resultant supernatant was frozen until it was assayed.

\section{(3) Radioimmunoassay (RIA)}

The concentrations of rat luteinizing hormone $(\mathrm{rLH})$, rat follicle-stimulating hormone (rFSH) and rat prolactin (rPRL) were measured by RIA, using the RIA kit distributed by NIADDK. LH and FSH were iodinized by chloramine T method (Hunter and Greenwood, 1962) and PRL was iodinized by lactoperoxidase method (Sakai, 1975). rLH, rFSH and rPRL were expressed in terms of the standard preparations of NIADDK-rLH-RP-2, NIADDK-rFSH-RP-2 and NIADDK-rPRL-RP-2, respectively.

\section{(4) Statistical analysis}

The data were expressed as the mean \pm SE. Student's $t$-test was used for comparison.

\section{Results}

In the preliminary experiments, the addition of $\mathrm{GnRH}$ in the range between $10^{-10} \mathrm{M}$ and $10^{-7} \mathrm{M}$ increased the release of $\mathrm{LH}$ in a dose-dependent manner after 48 hours of culture. At $10^{-7} \mathrm{M}$ of $\mathrm{GnRH}$, the concentration of LH was about 6 times as high as those in the absence of GnRH.
Then the effect of the addition of PRL on the release of $\mathrm{LH}$ was examined. As shown in Fig. 1, PRL increased LH levels in the medium regardless of the presence of $\mathrm{GnRH}$. The addition of PRL at $20 \mu \mathrm{g} / \mathrm{ml}$ produced $62 \%$ increase in $\mathrm{LH}$ levels in the absence of $\mathrm{GnRH}$, and $72 \%$ in the presence of GnRH.

Since the release of $\mathrm{LH}$ is influenced by estrogen at the pituitary level, it is of interest to see whether or not the addition of estradiol modulates the effect of PRL on the release of LH. As shown in Fig. 2, the stimulatory effect of PRL on LH release was more pronounced following the addition of estradiol at both $10^{-9} \mathrm{M}$ and $10^{-8} \mathrm{M}$. Therefore, subsequent experiments were carried out using the medium supplemented with estradiol $\left(10^{-9} \mathrm{M}\right)$ and $\mathrm{GnRH}\left(10^{-8} \mathrm{M}\right)$.

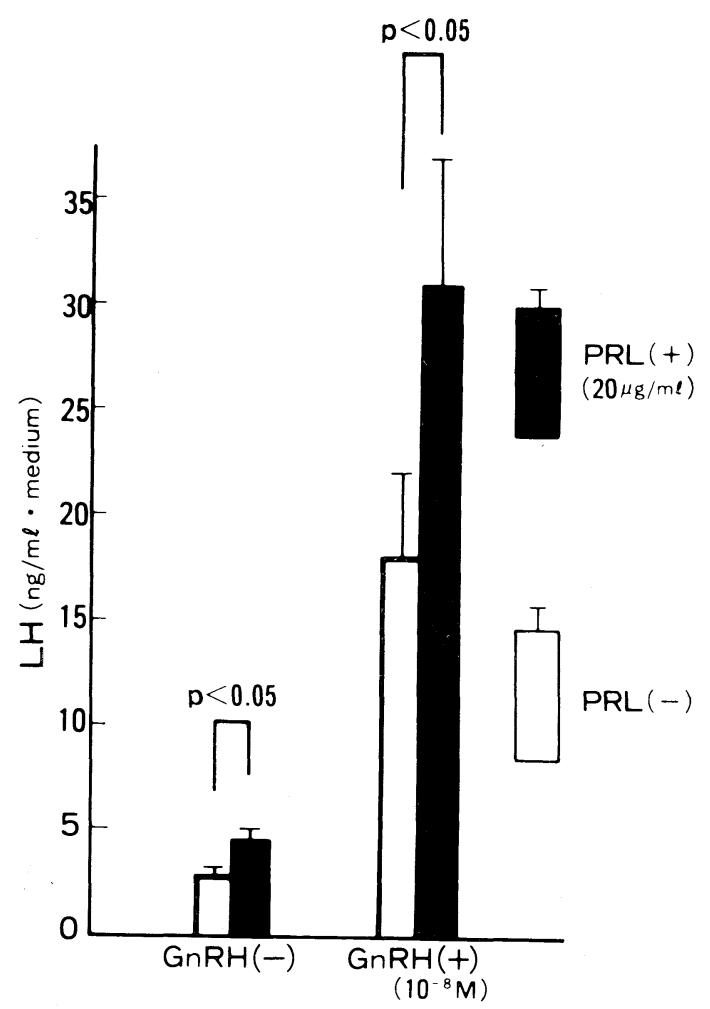

Fig. 1. Effects of PRL on the release of $L H$ with or without GnRH in cultured rat pituitary cells. (mean \pm SE) 


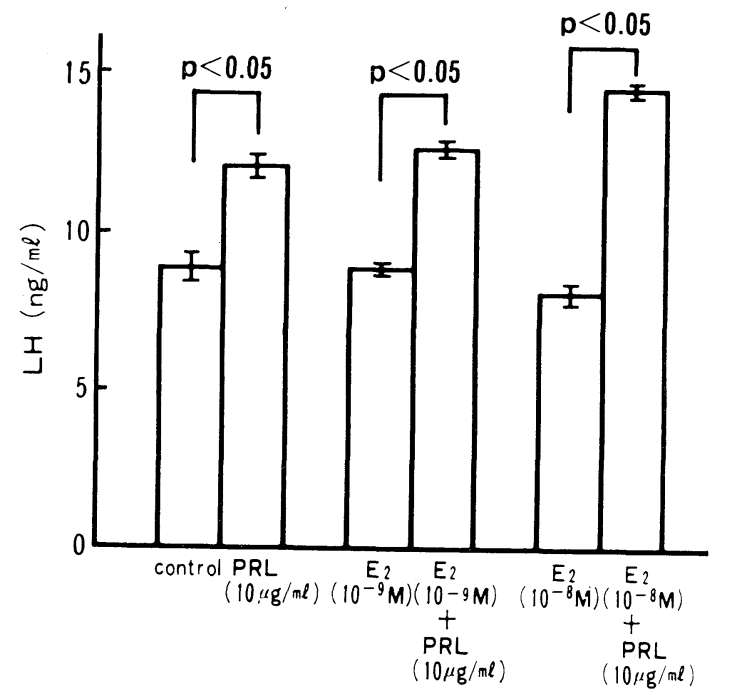

Fig. 2. Effects of PRL on the release of $\mathrm{LH}$ with or without estradiol $\left(E_{2}\right)$ in cultured rat pituitary cells.

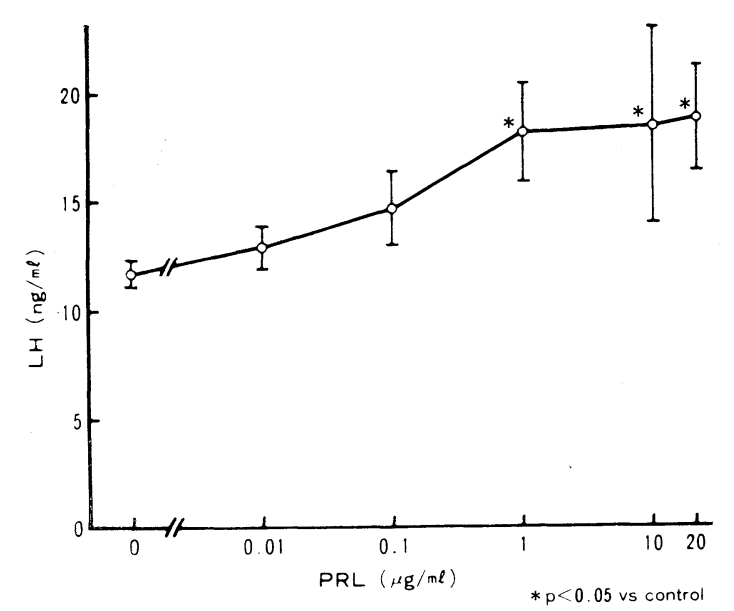

Fig. 3. Effects of different concentrations of PRL on the release of $L H$ in cultured rat pituitary cells. (mean \pm SE)

The effects of different concentrations of PRL on the release of LH were investigated (Fig. 3). The addition of PRL augmented the release of LH dose-dependently over the range $10 \mathrm{ng} / \mathrm{ml} \sim 1 \mu \mathrm{g} / \mathrm{ml}$. The concentration of $\mathrm{LH}$ in the medium containing $1 \mu \mathrm{g} / \mathrm{ml}$ of PRL increased by $60 \%$ compared with that without PRL.

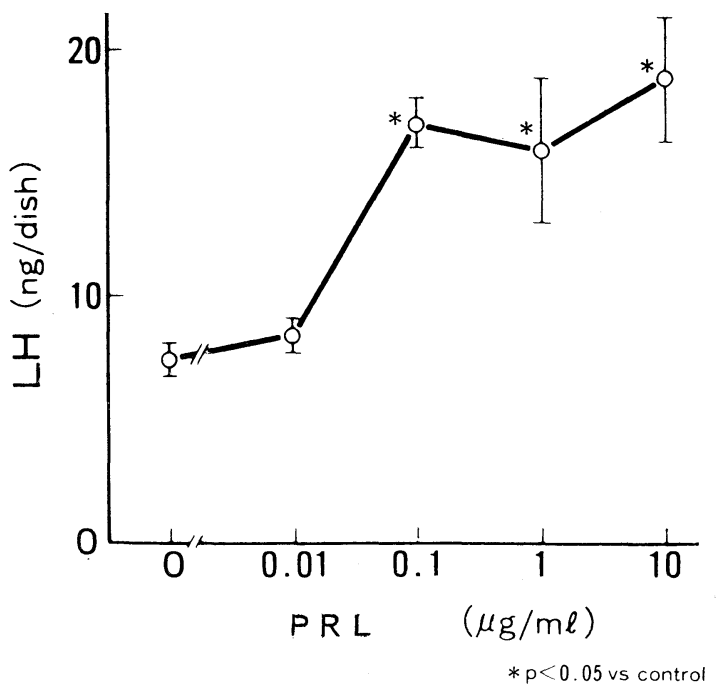

Fig. 4. Effects of different concentrations of PRL on the intracellular content of $\mathrm{LH}$ in cultured rat pituitary cells. (mean $\pm \mathrm{SE}$ )

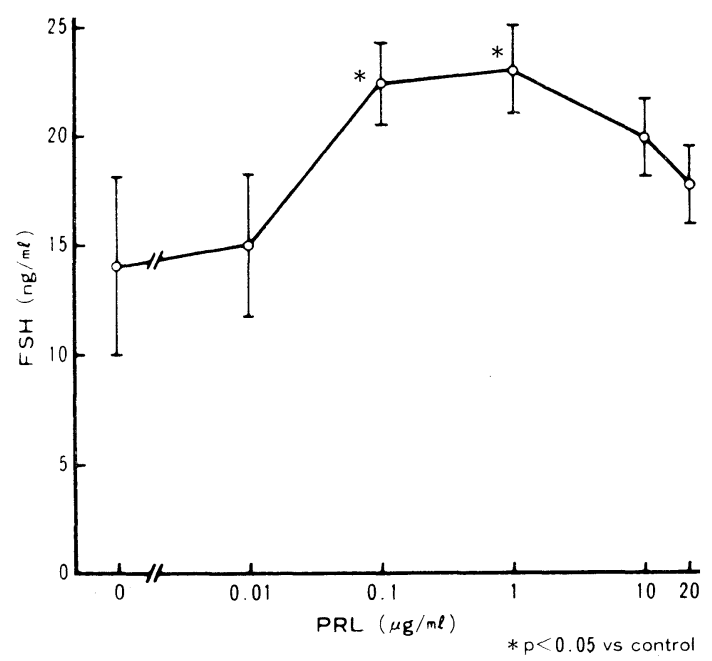

Fig. 5. Effects of different concentrations of PRL on the release of FSH in cultured rat pituitary cells. (mean \pm SE)

The amount of $\mathrm{LH}$ in cultured cells was measured. Fig. 4 shows that the intracellular content of $\mathrm{LH}$ was doubled by the addition of PRL at $0.1 \mu \mathrm{g} / \mathrm{ml}$ when compared with that without PRL. From these results, PRL may act to stimulate 
both the synthesis and the release of $\mathrm{LH}$,

The secretion of FSH was also increased by PRL. The addition of PRL caused a $60 \%$ increase in the concentration of $\mathrm{FSH}$ over the control (Fig. 5). However, unlike $\mathrm{LH}$, the FSH content in cultured cells was not influenced by the addition of PRL.

\section{Discussion}

Since hyperprolactinemia is often associated with various types of menstrual disorder, PRL has been considered to have suppressive effects on gonadotropin secretion. Presumptive mechanisms of suppressed gonadotropic function by PRL have been reported to be the interruption of the release of GnRH (Bohnet et al., 1976; Aono et al., 1976; Taketani et al., 1988) and the direct inhibition of ovarian function (McNatty et al., 1974; Demura et al., 1982; Van der Schoot et al., 1982). In this context, our present data showing a stimulatory action of PRL on gonadotropin release are rather unexpected.

Several earlier reports described blunted gonadotropin response to $\mathrm{GnRH}$ in women bearing PRL-producing adenomas (Nillius and Wide, 1972; Montimer et al., 1973; Coscia et al., 1974). However, the tumors in these cases were large enough to destroy most of the pituitary gland. Therefore, it is not pertinent to investigate the interaction between the secretion of PRL and gonadotropins. On the other hand, normal or exaggerated response of $\mathrm{LH}$ and FSH has been reported in women with PRLproducing microadenoma (Chang et al., 1977; Monroe et al., 1981). The exaggerated response has also been documented in women with idiopathic hyperprolactinemia (Archer et al., 1976). Our present results showing a possible stimulatory effect of PRL on gonadotropin secretion may be helpful in understanding how gonadotropin secretion is altered in women with hyperprolactinemia.
Hetzel et al. (1987) failed to observe any effect of PRL on LH release after 6 hours of preincubation of PRL in a cell culture of rat anterior pituitary gland. However, in the present study, the amount of $\mathrm{LH}$ release was determined in the presence of PRL for 48 hours. A likely explanation for these discordant data is the difference in the duration of incubation with PRL. Another possibility is the difference in the species of PRL tested: i. e. rat PRL $(50 \sim 500 \mathrm{ng} / \mathrm{ml})$ in Hetzel's study and ovine PRL $(1 \sim 10 \mu \mathrm{g} / \mathrm{ml})$ in this study.

The present findings are of interest considering the fact that gonadotroph is topographically in close association with lactotroph. This topographical relationship suggests the existence of a functional correlation between the two cells. This hypothesis was substantiated by Denef and Andries (1983) who demonstrated that gonadotrophs could activate the secretory activity of lactotrophs through the release of a paracrine factor. In contrast, in this study, PRL was shown to stimulate the release of LH. Taken together, it appears that gonadotrophs and lactotrophs are functionally coupled by enhancing the mutual secretory activity.

A preovulatory increase in estradiol is a prerequisite for the ensuing $\mathrm{LH}$ surge which triggers ovulation. Currently, it is known that estradiol potentiates gonadotropin release at the pituitary (Greeley et al., 1975) and hypothalamic levels (VilchezMartinez et al., 1974). Here, we have shown that the concomitant addition of estradiol augments the stimulatory action of PRL in releasing gonadotropin. Therefore, it is conceivable that PRL may be involved in a positive estrogen feedback mechanism for the LH surge at the pituitary level.

The way in which PRL stimulates the release of gonadotropin remains to be clarified. In an earlier work, it was observed that gonadotrophs were surrounded 
by lactotrophs, with gap junctions being formed between them (Fletcher et al., 1975). The topographical relation of the two cell types leads us to suggest that PRL released from lactotrophs acts directly on the gonadotrophs and stimulates the secretion of gonadotropin under the physiological conditions. However we cannot rule out an alternative mechanism. For example, PRL may release a humoral factor from unidentified cells other than gonadotrophs and then this factor may act on gonadotrophs to release gonadotropin. Whatever the mechanism may be, PRL exerts its action without any interaction with $\mathrm{GnRH}$, since the stimulatory effect of PRL can be observed in the absence of GnRH. Data not presented here show the presence of specific PRL-receptors on the anterior pituitary gland. The receptor for PRL may be responsible for the action of PRL on gonadotropin secretion.

\section{References}

Aono, T., A. Miyake, T. Shioji, T. Kinugasa, T. Onishi and K. Kurachi (1976). Impaired $\mathrm{LH}$ release following exogenous estrogen administration in patients with amenorrheagalactorrhea syndrome. J. Clin. Endocrinol. Metab. 42, 696-702.

Archer, D. F., J. W. Sprong, H. R. Nankin and J. B. Josimovich (1976). Pituitary gonadotropin response in women with idiopathic hyperprolactinemia. Fertil. Steril. 27, 1158-1164.

Bohnet, H. G., H. G. Dahlén, W. Wuttke and H. P. G. Schneider (1976). Hyperprolactinemic anovulatory syndrome. J. Clin. Endocrinol. Metab. 42, 132-143.

Chang, R. J., W. R. Keye Jr., J. R. Young, C. B. Wilson and R. B. Jaffe (1977). Detection, evaluation and treatment of pituitary microadenomas in patients with galactorrhea and amenorrhea. Am. J. Obstet. Gynecol. 128, 356-363.

Coscia, A. M., N. Fleischer, P. K. Besch, L. P. Brown and D. Desiderio (1974). The effect of synthetic luteinizing hormone-releasing factor on plasma LH level in pituitary disease. J. Clin. Endocrinol. Metab. 38, 83-88.

Demura, R., M. Ono, H. Demura, K. Shizume and $\mathrm{H}$. Ouchi (1982). Prolactin directly inhibits basal as well as gonadotropin-stimulated secretion of progesterone and $17 \beta$-estradiol in the human ovary. J. Clin. Endocrinol. Metab. 54, 1246-1250.

Denef, C. and M. Andries (1983). Evidence for paracrine interaction between gonadotrophs and lactotrophs in pituitary cell aggregates. Endocrinol. 112, 813-822.

Fletcher, W. H., N. C. Anderson Jr. and J. W. Everett (1975). Intercellular communication in the rat anterior pituitary gland. J. Cell. Biol. 67, 469-476.

Greeley Jr., G. H., M. B. Allen Jr. and V. B. Mahesh (1975). Potentiation of luteinizing hormone release by estradiol at the level of the pituitary. Neuroendocrinol. 18, 233-241.

Hetzel, W. D., P. M. Schneider and E. F. Pfeiffer (1987). Further evidence that prolactin does not affect gonadotropin release at the pituitary level. Horm. Metabol. Res. 19, 555562.

Hunter, W. M. and F. C. Greenwood (1962). Preparation of iodine-131 labelled human growth hormone of high specific activity. Nature 194, 495-496.

McNatty, K. P., R. S. Sawers and A. S. McNeilly (1974). A possible role for prolactin in control of steroid secretion by the human Graafian follicle. Nature (London) 250, 653-655.

Monroe, S. E., L. Levine, R. J. Chang, W. R. Keye Jr., M. Yamamoto and R. B. Jaffe (1981). Prolactin-secreting pituitary adenomas. V. Increased gonadotroph responsivity in hyperprolactinemic women with pituitary adenomas. J. Clin. Endocrinol.Metab. 52, 11711178.

Montimer, C. H., G. M. Besser, A. S. McNeilly. J. C. Marsha1l, P. Harsoules, M. G. Tunbridge, A. Gomez-Pan and R. Hall (1973). Luteinizing hormone and follicle stimulating hormonereleasing hormone test in patients with hypothalamic-pituitary-gonadal dysfunction. $B r$. Med. J. 4, 73-77.

Nillius, S. J. and L. Wide (1972). The LHreleasing hormone test in 31 women with secondary amenorrhea. J. Obstet. Gynecol. Br. Emp. 79, 874-882.

Sakai, S. (1975). A receptor site for prolactin in lactating mouse mammary tissues. Endo- 
crinol. Japon. 22, 379-387.

Taketani, Y., N. Hayashi, K. Kugu and M. Mizuno (1988). Effect of prolactin administration on LH, FSH and GnRH in ovariectomized rats. In: Role of prolactin in human reproduction (M. Mizuno, H. Mori, and Y. Taketani eds.), Karger, Basel. pp. 91100.

Van der Schoot, P., D. den Besten and J. Th.
J. Uilenbroek (1982). Atresia of preovulatory follicles in rats treated with sodium pentobarbitol: effects of bromocriptine. Biol. Reprod. 27, 189-199.

Vilchez-Martinez, J. A., A. Arimura, L. Debeljuk and A. V. Schally (1974). Biphasic effect of estradiol benzoate on pituitary responsiveness to LH-RH. Endocrinol. 94, 1300-1303. 